\title{
Afeto e comunicação: sobre as construções do medo ${ }^{1}$
}

\author{
Maria Cristina Franco Ferraz
}

Resumo: $\mathrm{O}$ artigo dedica-se, de início, a um conceito presente em estudos atuais em Comunicação e Cultura: o de afeto. Partindo da filosofia deleuzeana, tematiza o conceito, discute questões de linguagem e privilegia um feixe de afetos, provisoriamente chamado de "medo", com base no conto de Kafka intitulado A construção (1923). A leitura do conto permite articular medo, insegurança e risco ao gesto de construir moradas ou habitats. O tema é desdobrado em um texto de Nietzsche no qual se avaliam diferentes tipos de construção, vinculando-os a certas perspectivas e pulsões vitais. Na esteira de Nietzsche, elegem-se duas construções como apostas para a visada teórica: andaime e brinquedo.

Palavras-chave: afeto; risco; medo; vida; Kafka.

Abstract: Affect and communication: on the constructions of fear - The paper discusses a concept which is present in recent studies in the fields of Communication and Culture: affect. It refers to the Deleuzean concepts of affect, and discusses questions of language concerning affects. From those philosophical basis and discussions, complex affects - named as "fear" - are examined, by means of a close reading of Franz Kafka's short story "Der Bau/The Construction" (1923). This fictional text articulates notions such as fear, insecurity and risk to the need for constructing houses and habitats. This theme is related to a Nietzschean essay in which the philosopher evaluates different types of constructions and relates them to vital pulsions. Following Nietzsche, two constructions are used as inspirations to the theoretical work: scaffold and toy.

Keywords: affect; risk; fear; life; Kafka.

O conceito filosófico de afeto tem sido convocado pelo campo de estudos em comunicação e cultura. Sem dúvida, a disseminação da filosofia deleuzeana, tanto nas artes contemporâneas quanto na Comunicação (especialmente em estudos de cinema), tem favorecido a penetração desse conceito que, conforme operado por Gilles Deleuze, se afasta de noções mais usuais e psicologizantes, como as de sentimento e emoção. O intuito deste artigo é o de contribuir para os estudos na área, partindo da retomada do

1 Este artigo foi apresentado no GT "Comunicação e Sociabilidade" no XXV Encontro Nacional da Compós, em Goiânia, em junho de 2016. 
conceito deleuzeano para investigar em seguida, com base em um conto de Kafka, uma teia de afetos significativamente presente na cultura ocidental, na contemporaneidade e que, para simplificar, chamaremos de "medo". O medo será então articulado ao ato de construir moradias.

A escolha dessa esfera de afetos nada tem de arbitrária. Após os ataques terroristas de Paris, em novembro de 2015, no cenário de ameaças permanentes de novos atos terroristas e também por conta da crise migratória de fugitivos de regiões empobrecidas e deflagradas, espraia-se na Europa ainda mais o medo - medo também do outro -, favorecendo guinadas políticas conservadoras. No Brasil, o alardeamento incessante de crises e falências econômicas e políticas tem alimentado o medo, instrumentalizado por meios de comunicação de orientação conservadora. Torna-se portanto oportuno tematizar os inumeráveis tentáculos do medo, tentando nos deixar menos à mercê de suas inclinações e implicações políticas e existenciais.

Exploremos o conceito de afeto. Quando se fala em afeto, é inevitável lembrar a filosofia de Spinoza. Entretanto, como o conceito penetrou o pensamento atual sobretudo por meio de Deleuze e Guattari, irei me ater, no escopo deste ensaio, à elaboração conceitual efetuada por esses filósofos do século XX. A referência será aqui o penúltimo capítulo de $O$ que é a filosofia, dedicado à distinção entre afetos, perceptos e conceitos (DELEUZE e GUATTARI, 1991, pp. 211-255). A certa altura, os filósofos afirmam que o que resta de uma obra de arte são "blocos de sensações", compostos por perceptos e afetos. Definem perceptos como "paisagens não humanas da natureza" e afetos como "devires não humanos do homem" (DELEUZE e GUATTARI, 1991, p. 220). De saída, ficam marcadas tanto a distância com relação ao humano - ecoando Nietzsche: "humano, demasiado humano" - quanto a aposta no que a linguagem e os sentidos comuns não "humanizaram" nem domesticaram, deixando-o emergir em sua estranheza e alteridade radical.

Nessa definição, intervém uma noção de tempo não humanizada, isto é, não linear ou espacializada. Essa dimensão - o "devir", neologismo calcado no francês devenir ${ }^{2}$ - é bergsonianamente remetida a um movimento absoluto e contínuo, a espessuras temporais permanentemente atravessadas por mudanças infinitesimais de ritmos, de vibrações (cf. BERGSON, 2001; FERRAZ, 2010). Se para compor "blocos de sensações" é preciso desfamiliarizar a natureza, produzindo o percepto (distinto da percepção usual, ligada à "atenção à vida" - outra noção bergsoniana), é igualmente necessário surfar devires, penetrar dimensões de tempo moduladas e vibráteis, desprendendo-se de sentidos e temporalidades humanizadas, atrelados à necessidade de viver e de agir em um mundo compartilhado.

2 A tradução mais direta de "devenir" (ou do alemão Werden, também muito presente no discurso filosófico) seria "tornar-se", verbo em nossa língua por demais comprometido com uma concepção de mudança tão-somente relativa, já que a forma reflexiva (o pronome "se") embute uma instância imóvel que entraria em movimento. Na medida em que pressupõe um sujeito fixo, "tornar-se" é filosoficamente inadequado nesse caso. "Devir", por vezes traduzido por "vir-a-ser" (solução a meu ver menos adequada, até por conta de sua morfologia), é mais compatível com a noção de tempo como movimento absoluto, indivisível, em fluxo contínuo. 
Os autores concluem a passagem com a seguinte definição do que seria o "estilo": alçar percepções vividas ao percepto e afecções vividas ao afeto. Ou seja: percepto e afeto se apartam do âmbito do vivido. Não que aquilo que se vive esteja alijado do processo. Como sabia Nietzsche, uma vez que "o mais profundo ama a máscara" (Além do bem e do mal, § 40) (1992), é preciso liberar as vivências das coagulações de sentidos já dados, homogeneizantes e simplificadores, para fazer passar para o plano da expressão algo da singularidade efetivamente experienciada. Introduz-se, neste ponto, uma questão incontornável: a problemática da linguagem comum. Quando afirma, no Crepúsculo dos ídolos ${ }^{3}$, que ao falarmos nos banalizamos, nos vulgarizamos, Nietzsche sintetiza reflexões desdobradas em várias de suas obras. Para o filósofo, como os sentidos cristalizados em uma língua ou cultura resultam de processos de abstração, de homogeneização e de simplificação, o âmbito do singular não se deixa apreender ou exprimir pelas malhas cerradas dos sentidos partilhados e naturalizados. Daí a aposta nietzschiana nas máscaras, na ficcionalidade e na invenção, em suma, na mais alta potência do falso, para expressar "o mais profundo", o singular, a experiência intransferível. Eis porque é necessário compor blocos de sensações.

A questão da comunicabilidade banalizadora afeta diretamente nosso tema, na medida em que impõe, de saída, a seguinte questão: de que maneira podemos nomear afetos, quando pretendemos tematizá-los teórica e filosoficamente? Se afetos acompanham vivências singulares, únicas; se convocam temporalidades duracionais, sempre em movimentos infinitesimais, em contínua alteração rítmica, colocam necessariamente em xeque a nomeação comum. Esta secciona, compartimenta e concede estabilidade ao que sempre se dá como modulações afetuais, a fim de fixar o movente e facilitar a ação vitalmente orientada. De que modo então encontrar palavras para o que escapa à fixidez? Quando dizemos "tristeza", por exemplo (termo em vias de se tornar anacrônico, cada vez mais substituído pelo somático "depressão"), achatamos incontáveis movimentos imperceptíveis, aplainamos as infinitas modulações do afeto que, como tal, se esquiva à nomeação estanque e estabilizadora.

O modelo musical pode funcionar como sintoma dessa problemática e como pista para outras vias. Com vistas à execução de variações de andamento em uma peça musical, usaram-se termos italianos, tais como Adagio, Allegro, Vivace, Presto, que podem ainda se compor em sugestivas combinações, como Adagio melancolico, Allegro moderato ou Presto con fuoco. Ou ainda o sugestivo Allegro ma non troppo, un poco maestoso, que singulariza o famoso primeiro movimento da Nona sinfonia de Beethoven. A linguagem dos afetos está aí expressa. São por vezes necessárias várias justaposições e especificações

3 Citando a íntegra do aforismo 26 da seção "Divagações de um inatual", em minha tradução: "Não nos estimamos suficientemente quando nos comunicamos. Nossas vivências mais próprias nada têm de tagarelas. Não poderiam se comunicar se quisessem. Isso porque lhes falta a palavra. Aquilo para o que temos palavras, já o ultrapassamos. Em todo discurso há algo de desprezo. A língua só foi inventada, ao que parece, para o mediano, o medíocre, o comunicável. Pela linguagem, já se vulgariza o falante. - Extraído de uma moral para surdos-mudos e outros filósofos." (NIETZSCHE, 1988, vol. 6, p. 128). 
para implodir sentidos fixados e fazer fluirem afetos musicais. Conforme sabia Guimarães Rosa, para dar conta dos afetos e suas estranhezas, a linguagem comunicável precisa inventar terceiras margens, embarcar no puro fluir, esposando o devir. Ao explorar teoricamente afetos, não podemos, portanto, perder de vista (ou de ouvido) as modulações de andamento, intensidade e ritmo que singularizam tanto a execução da música quanto os afetos que atravessam os corpos.

Deleuze e Guattari assinalam que, procurando expressar a singularidade do vivido, o artista e o romancista necessitam fazer estados perceptivos e passagens afetivas singulares transbordarem para outras palavras ou imagens. Os autores citam Giacometti, para quem o artista precisa liberar a vida onde ela é prisioneira, o que implica a invenção de novas linguagens (DELEUZE e GUATTARI, 1991, p. 222). É empobrecedor nomear afetos pelo diapasão estabelecido, pois o afeto não se confunde com a passagem de um estado vivido a outro, dizendo respeito a variações em fluxo. Em geral, nomeiam-se estados que se sucedem, variando em grau, tal como na sequência possível tristeza-melancolia-desespero. A questão que concerne aos afetos, entretanto, não diz respeito a esses estados, que são como pontos de chegada, mas a uma linha indivisível que é pura transformação, a feixes de modulações em curso.

Em certos quadros de De Chirico, por exemplo, emergem cidades, estranhos cenários urbanos desabitados e ao mesmo tempo familiares. É esse "ao mesmo tempo" que interessa neste caso. Eis um exemplo de "paisagem não humana", inserida no cerne das construções humanas, como as ruas de uma cidade. Conexões inauditas introduzem uma lógica outra, já não calcada no reconhecimento por semelhança, mas em "uma extrema contiguidade, em um enlaçamento entre duas sensações sem semelhança" (DELEUZE e GUATTARI, 1991, p. 224-225). Trata-se de produzir zonas de indeterminação, regiões de indiscernibilidade; blocos de sensações, compostos de perceptos - que se distinguem das percepções vividas - e de afetos, entendidos como transmutações artísticas de afecções vividas.

Afetos e perceptos se afastam da "humanização" e do mero reconhecimento. Em O que é a filosofia, Deleuze e Guattari afirmam que "a arte não cessará de ser assombrada pelo animal" (1991, p. 238). Sublinham que ela talvez comece com o animal, especialmente com a marcação de um território e a construção de uma casa; em suma, de um habitat, fusão entre território e casa (DELEUZE e GUATTARI, 1991, p. 237). Referem-se então à obra de Kafka como a mais profunda meditação sobre o território e a casa (DELEUZE e GUATTARI, 1991, p. 238), parecendo ter em mente um dos últimos textos escritos por Kafka, no final de 1923, intitulado "A construção" (Der Bau) ${ }^{4}$.

Para precisarmos o conceito de afeto e essa pista deixada pelos filósofos, exploremos o conto, investigando as relações entre a construção de casas, de habitats, e uma pletora de afetos que, para simplificar, chamaremos de "medo". Conforme já enfatizado,

4 Para toda referência a esse conto, remeterei à tradução de Modesto Carone (Kafka, 1984), cotejada com o original alemão, a fim de aproximá-la ainda mais do texto de Kafka (Kafka, 1988). 
o problema da linguagem, por conta da aliança entre gramática e metafísica (cf. NIETZSCHE, 1998), torna problemática a nomeação de afetos. O emprego da palavra "medo" aqui convoca um gesto nominalista aproximável daquele pleiteado por Michel Foucault, no capítulo "Método" de História da sexualidade I (FOUCAULT, 2009, p. 102108). Foucault utiliza a palavra gasta "poder" (no singular) para erigir um novo conceito, referido a uma trama múltipla, heterogênea, sempre movente, tecida por tensões e lutas entre forças. A perspectiva nominalista equivale à apropriação de um termo banal para fazê-lo apontar para novas direções do pensamento. Mantenhamos por ora e de modo nominalista a palavra "medo", sem perder de vista a multiplicidade heterogênea e cambiante de ritmos afectuais que ela implica.

O conto "A construção" é um monólogo interior, um fluxo de pensamento ininterrupto de um vivente que, sem ser humano, raciocina, racionaliza de modo contínuo. Tampouco se define como um animal específico, lembrando por vezes uma toupeira, uma raposa, ou qualquer animal que construa seu habitat em tocas e túneis labirínticos debaixo da terra. Essa ardilosa mistura de extrema humanização (situada e extraviada nos meandros do discurso, da consciência e da racionalidade) e total animalidade (tocas, focinho-testa construtora, acúmulo de provisões que apodrecem sem cozimento) torna o narrador indecidível, ampliando a problemática das construções para a esfera de todo vivente. Ou seja, a humanidade e suas construções nada teriam de excepcionais ou de superiores. Certo desamparo e a necessidade de proteção seriam extensivos a várias espécies de viventes. O expediente kafkiano de tornar indecidivelmente humana e animal a enunciação do monólogo tem dois efeitos intensificadores: se por um lado torna estranhos tanto homens quanto animais, por outro os aproxima na idêntica necessidade de construir e na miríade de afetos vinculados a esse gesto.

O curioso vivente explica que, por artimanha, construiu falsas entradas para sua toca labiríntica e manteve apenas uma verdadeira, recoberta por uma camada de musgo removível. O que deveria servir para sua proteção e segurança, representa de imediato uma nova ameaça (alguém pode descobrir e penetrar na morada) e produz constante inquietação: "não tenho uma hora de completa tranquilidade, pois naquele ponto escuro do musgo sou mortal e nos meus sonhos muitas vezes ali fareja, sem parar, um focinho lúbrico" (KAFKA, 1984, p. 64). Introduz-se, desde o início, um amálgama de afetos inextricáveis, em que estão presentes: desamparo, inquietação, desejo de segurança, necessidade de construir, proteção, prudência, astúcia, reintrodução do risco, do medo e sensação de vulnerabilidade ("naquele ponto escuro do musgo sou mortal"). A conclusão é precisa, lapidar: "justamente a precaução exige que eu tenha a possibilidade de uma saída instantânea, justamente a precaução exige, como infelizmente com tanta frequência, o risco da vida" (KAFKA, 1984, p. 64). O medo aciona um circuito tautológico e tão labiríntico quanto a toca permanentemente escavada. 
Kafka, que trabalhara em uma companhia de seguros, bem conhecia os meandros paradoxais da ideologia securitária. Como se sabe, não há expediente ou dispositivo de proteção que não produza novos riscos ${ }^{5}$, em uma engrenagem circular e sem saída. Nessa espiral diabólica, a necessidade de proteção engendra estratégias que, por sua vez, introduzem novos perigos. Basta lembrar que são frequentemente caseiros, vigias e guarda-costas que, por estarem mais próximos, se tornam os mais eficazes para assassinar, sem qualquer empecilho, aqueles que deveriam proteger. Para um exemplo recente: em 2015, um novo procedimento antiterror ganhou um uso a contrapelo. Como precaução suplementar a atos terroristas em aviões, o acesso a cabines de pilotos passou a ser fechado por fora, só se permitindo a entrada ao abrir-se por dentro. Essa nova medida preventiva serviu ao copiloto do avião da companhia alemã Germanwings que, no ano passado, suicidou-se arremessando o avião contra os Alpes franceses, matando 150 pessoas.

A engrenagem medo-segurança-risco se atualiza no conto em uma espiral sufocante, gerando um discurso que poderíamos caracterizar como paranoide. Afinal, o animal está sempre se sentindo à mercê tanto de inimigos externos quanto de pequenos animais que habitam a terra em que constrói seus túneis. Chega mesmo a pensar que talvez nem esteja em sua casa, mas na deles. Enquanto cava e aprimora incansavelmente seu território sempre em construção, é bastante presente a possibilidade de sentir, de repente, "os dentes do perseguidor" em suas coxas (KAFKA, 1984, p. 65). Não cabe entretanto categorizá-lo como "paranoico" apenas para nos protegermos da pressão angustiante do monólogo desse animal construtor ou da asfixia nos labirintos de seus raciocínios técnicos. É bem mais produtivo, teórica e filosoficamente, investigar de que modo funciona essa engrenagem no texto e o que ela nos permite pensar sobre nosso tempo e modos de ser.

Uma vez que o esforço por segurança é contínuo e jamais de todo assegurado, o animal construtor não cessa de cavar novos túneis, em sua construção infinita e interminável. O que de início representava um meio de assegurar sua sobrevivência e tranquilidade, tira-Ihe paulatinamente o sono e o sossego, tornando-se um fim em si mesmo e passando a ocupar todo o seu viver. Nesse sentido, o animal kafkiano antecipa modos de vida non-stop e insones, diagnosticados por Jonathan Crary no livro 24/7: capitalismo tardio e os fins do sono (CRARY, 2013). A insônia está ligada tanto ao sistema de produção e de acirrada competitividade quanto à corrosão de uma condição essencial para o sono tranquilo: ao menos alguma confiança no outro e no mundo.

Bem antes da virada do capitalismo em direção ao regime pós-industrial, de matriz financeira e ancorado em fluxos de informação em tempo real, a ciranda do risco, do medo insone já ritmava os esforços incansáveis do construtor kafkiano. Ele também

5 Os labirintos do medo ganharam expressão teórica em obras como as de Ulrich Beck (2011), que tematizou a "sociedade de risco", e Alain Badiou (2010), que destacou a ideologia securitária que pauta práticas sociais contemporâneas, permeando relações amorosas oferecidas em sites de relacionamentos. A noção de risco tem sido explorada e remetida à mídia, especialmente às redes sociais, por pesquisadores como Paulo Vaz (Vaz e Cardoso, 2011) e leda Tucherman (2015). 
é movido por um impulso acumulativo irrefreável: estoca provisões, restos de animais de que, por precaução, pouco se serve. Talvez por isso ele também compareça no breve texto acerca da sociedade de controle, quando Deleuze chama o animal dos confinamentos disciplinares, diverso da serpente do controle, de "velha toupeira monetária" (DELEUZE, 1992, p. 222). Se a "toupeira" acumula incessantemente no conto, evitando o próprio consumo, as ciladas do medo, o temor constante ao risco serpenteiam pelos meandros da toca, prenunciando a insônia gerada pelo controle, acrescida às velhas pressões próprias ao confinamento disciplinar. Foi também nesse sentido que Deleuze e Guattari consideraram Kafka um escritor "político, adivinho do mundo futuro" (DELEUZE e GUATTARI, 1975, p. 75). Segundo os autores, Kafka se pretendia menos um espelho - metáfora clássica do mimético, do ficcional - do que um "relógio que avança" (p. 107).

Desde o início da narração, o animal salienta a importância do silêncio, de uma certa paz em sua morada. Se o faz, é entretanto apenas para afirmar que essa tranquilidade está constantemente ameaçada: "Mas a coisa mais bela da minha construção é o seu silêncio. Certamente ele é enganoso. Pode ser interrompido de repente e então tudo se acaba." (KAFKA, 1984, p. 65-66). A iminência da perda e da dissolução de tudo o que se planejou e construiu não vem a reboque do projeto; parece inerente ao próprio impulso construtor. Acompanha os sucessos da obra como uma sombra sempre presente, à espreita. Os avanços e aperfeiçoamentos da construção alimentam o medo também por conta da entrega de toda a vida à tarefa de construir.

No monólogo, cada possível conquista resulta imediatamente em logro. Como, por exemplo, no trecho acima citado: o ideal de paz, motor das construções protetoras, só é mencionado para ser suspenso, interrompido e inviabilizado. A paz e o sono vão sendo progressivamente minados. Sempre alerta, acossado pelos perigos que imagina poderem emergir de todos os lados, o vivente já não consegue usufruir dos cantos aconchegantes projetados para seu descanso:

A cada cem metros ampliei os corredores em pequenos cômodos redondos, neles posso me enrodilhar confortavelmente [...] e descansar. Lá eu durmo o doce sono da paz, do desejo pacificado, do alvo atingido de possuir uma casa. [...] de tempos em tempos, regularmente me assusto e saio do sono profundo e fico escutando... (KAFKA, 1984, p. 66).

Lembremos que, no DVD "O abecedário de Deleuze", no qual a letra A é dedicada a "animal", Deleuze vincula seu interesse pelo animal ao curioso estado sempre "à espreita": mesmo quando o animal se alimenta, suas orelhas não cessam de se mover, buscando apreender o que estaria acontecendo por trás dele. No animal kafkiano, tal estado de alerta constante é intensificado e igualmente remetido ao sentido da audição.

Cada vez mais essa paz aparente, o território assegurador será corroído por novos medos e sobressaltos. Ao longo da narração, o animal afirma sentir saudades dos (míticos) 
tempos de juventude, em que dormia sereno. Quando sai em busca do que produz os ruídos que o deixam definitivamente inseguro dentro de casa, conclui de modo lúcido: "...por mais que procure, não encontro nada, ou melhor: encontro demais" (KAFKA, 1984, p. 87). Ele parece ter consciência de que o nada é o verdadeiro motor do medo. Não encontrar o inimigo - encontro quase que, nesse sentido, ansiado - só alimenta o medo. Também por isso, nada encontrar já é demais: o inimigo onipresente em ausência e que nunca chega, para o qual sempre se prepara, representa uma tortura sumplementar ${ }^{6}$. Na mesma afirmação, evidencia-se o absurdo nada que aciona a manivela do medo. Por isso é que, quanto mais constrói para proteger-se, o animal técnico mais se enreda e menos seguro fica. O desejo de segurança convoca, por si só, o imaginário de todos os perigos e riscos possíveis, que passam a estar onipresentes.

Ainda acerca do nada como motor da construção, eis de que modo o narrador define o rumor que destroça qualquer possibilidade de paz, mobilizando suas pesquisas e seus movimentos inquietos na toca: "O que é ele? Um leve zumbido, audível apenas em longas pausas, um nada ao qual não quero dizer que se pudesse acostumar..." (KAFKA, 1984, p. 93). Um nada. É esse nada que corrói qualquer paz e descanso que o projeto da construção idealmente propiciaria. Mesmo quando descreve raros momentos de fruição da toca, sempre desponta o verme da inquietação: "Tempos felizes, mas perigosos" (KAFKA, 1984, p. 70). A narração aciona uma máquina infernal: a cada nova esperança e promessa de distensão sucedem-se, imediatamente, sem que se possa respirar, novas ameaças sempre possíveis. À medida que se vão intensificando os ruídos, que ele perscruta e tenta desvendar, seu sono termina por não mais se conciliar.

Podemos então articular três elementos: casa, sono e silêncio. Os três vão sendo simultaneamente minados, à medida que pequenos ruídos - audíveis para as orelhas sempre à espreita desse animal acossado - vão penetrando na antiga paz, mais idealizada no passado do que efetivamente conquistada. O funcionamento do conto lembra, nesse sentido, o sugestivo filme "O som ao redor", de Kleber Mendonça Filho (2012). Trata-se de um som surdo que, apesar dos bunkers, ruas e condomínios fechados por seguranças, penetra pelos desvãos, pelo ar, desrespeitando fronteiras e limites demarcadores. O fim do descanso, da paz e do sono remetem tanto à invasão de sons, que suscitam novas e inúteis pesquisas sobre sua fonte, quanto à ausência total de confiança no outro e no mundo: "Confiança só posso ter em mim mesmo e na construção" (KAFKA, 1984, p. 80). A consciência implacável do risco arruína aquilo mesmo que justificaria o trabalho incessante e monstruoso:

6 Cabe lembrar, nesse sentido, as oportunas observações de Slavoj Žižek (Žižek, 2003) acerca da "onipresença paranóica da guerra invisível" (p. 53), bem como as relações (via a psicanálise lacaniana) que o autor estabelece entre filmes-catástrofe hollywoodianos, o ataque terrorista às Torres Gêmeas e fantasias de destruição: “... com que sonham os americanos abastados, imobilizados no seu bem-estar? Sonham com uma catástrofe global que viria a destruir suas vidas." (ibid., pp. 31-32). 
Mas o fato é que na realidade - para a qual não se dá a atenção necessária em situações de grande perigo, embora justamente nos tempos de ameaça seja preciso aguçá-la - a construção oferece, com efeito, muita segurança, mas absolutamente não o suficiente; acaso cessam nela sempre as preocupações? (KAFKA, 1984, p. 81).

O conto "A construção" apresenta várias outras facetas instigantes. Uma delas, talvez a mais perturbadora, reside no fato de que a consciência com relação aos ardis do medo e a seu caráter aporístico não basta para alterar a perspectiva do vivente construtor. Kafka abala, de modo radical, a crença moderna no poder da tomada de consciência para a mudança de atitudes e de vida. Vejamos duas passagens das mais inquietantes a esse respeito. Na primeira, o animal, que percorre os corredores da construção com os ouvidos colados às paredes, afirma que o faz "na realidade, não para descobrir alguma coisa, mas para fazer algo que corresponda ao desassossego interior." (KAFKA, 1984, p. 93). Um pouco mais adiante, desconfia que não esteja realmente ouvindo ruídos externos, uma vez que "o próprio sangue pulsa demais no ouvido" (KAFKA, 1984, p. 95). Ou seja: é o próprio pulsar da vida assustada desse insone construtor que preside ao regime do som ao redor. O inimigo que ronda sua casa ressoa em seu peito. A lucidez a respeito de seu desassossego não basta, entretanto, para curto-circuitar a espiral do medo; não basta para propiciar uma saída efetiva dos labirintos do medo. A consciência crítica acerca da insanidade e inutilidade do projeto de construção não abre novas possibilidades, anulando-se essa aposta moderna.

Cabe destacar um último aspecto do conto, antes de avançarmos no tratamento dos liames entre medo e construção. Trata-se da reificação do projeto: em princípio um meio de proteção, segurança e sobrevivência, a construção (paranoica, em sua intensificação no texto kafkiano) torna-se um único fim, uma finalidade última a ser conquistada. Já não importa perder a vida, contanto que "a construção" permaneça a salvo. O que vale, no final das contas, e mesmo às custas do construtor, não é sua própria proteção, mas a "defesa da construção" (KAFKA, 1984, p. 100). Tais afirmações não deixam de lembrar projetos políticos que pretenderam estender-se no tempo, como o Terceiro Reich, que, na década seguinte, prometia durar mil anos.

A problemática do medo atravessa diversas perspectivas filosóficas ocidentais, passando por Thomas Hobbes e chegando, contemporaneamente a Giorgio Agamben, que equacionou toda a política ao direito de eliminar qualquer vivente. Em um sentido ampliado, o medo foi remetido por Agamben às bases do poder instituído, que, garantindo para si o monopólio da violência, secreta a sensação de uma vida nua que pode ser assim expressa: se permanecemos vivos, é porque nos deixam continuar existindo (AGAMBEN, 1998). Esse pathos se encontra igualmente na abertura dos Fragmentos do discurso amoroso, de Roland Barthes, que se refere justamente a Thomas Hobbes ("A minha única paixão foi o medo"), filósofo que deu amplo espaço ao temor em suas reflexões 
políticas, no século XVII (RIBEIRO, 1999). A ideologia securitária que permeia a cultura contemporânea também se encontra problematizada, de modo original, pelo antropólogo brasileiro Eduardo Viveiros de Castro, em especial no artigo intitulado "O medo dos outros" (CASTRO, 2011). Deixando no entanto para outra ocasião o aprofundamento dessa abrangente teia filosófica, exploremos, a título de conclusão, um ensaio de Nietzsche publicado postumamente, dedicado ao tema da "Verdade e da mentira em um sentido extramoral", no qual o filósofo avalia diversos tipos de construções, remetendo-os a determinadas condições vitais. Por tratar de construções, esse ensaio se torna mais diretamente aproximável de nosso tema.

Nesse texto de 1873, Nietzsche (1969) desconstrói a distinção entre conceito e metáfora, privilegiando e ampliando a noção de metáfora - polo desqualificado da oposição - para denunciar o conceito como uma metáfora esquecida, recalcada, morta e incinerada. Caracterizando o conceito como um depositário de múmias, de cinzas de inventivas metáforas, aciona então uma série de metáforas arquitetônicas. Relaciona o conceito à pirâmide e ao columbário, local em que os romanos guardavam cinzas. Refere-se ao esquadrinhamento do céu em rígidas linhas matemáticas, efetuado por romanos e etruscos, transformando-o em um templum sob o qual se conjuravam deuses. Para o filósofo, todos os povos construíram, sobre suas cabeças, um céu de conceitos (Begriffshimmel) matematicamente escandido. O filósofo admira-se com o poderoso gênio arquitetônico do homem, que, por sobre um solo movente, erigiu um domo de conceitos (Begriffsdome) infinitamente complexo. Lembremos que a palavra "domo" deriva do grego doma, casa, de que também deriva despotes, inicialmente senhor, dono da casa, e posteriormente déspota. Doma está presente no verbo "dominar", diretamente derivado do latim dominus, senhor.

Construções dizem portanto respeito a tentativas de dominar, de domar o estranho, de se assenhorear das forças do acaso e da imprevisibilidade, exercendo certa forma de despotismo. Até aí, não há problema, pois também se trata de criar apoios necessários ao viver. A proposta nietzschiana implica, entretanto, a avaliação de tipos diferentes de construções, distinguindo "despotismos". O filósofo diferencia construções que fecham o mundo, a infinitude aberta do firmamento, das que se deixam penetrar e arejar. Se construir e abrigar-se é necessário para os viventes, a ilusão de controle que se traduz na rigidez, ligada à morte, e necessita da ilusão de solidez e segurança, bem como da ditadura dos sentidos previamente dados, indica certo enfraquecimento das forças pulsionais. Mesmo antes da criação de seu vocabulário propriamente genealógico - ligado à avaliação dos valores, em termos de forças vitais -, o filósofo considera que é o homem vitalmente empobrecido que necessita erigir construções e verdades inabaláveis, precisa fixar fundamentos sólidos para ancorar-se em um solo definitivamente assegurado, erigindo sua casa sob um firmamento efetivamente firme, ilusoriamente estabilizado. 
Nietzsche, que no parágrafo 1 do prefácio a Aurora se considerava uma toupeira que abala os alicerces do edifício da metafísica, passa a opor dois tipos de construção, avaliadas como a favor ou contra a vida, entendida como ausência de fundações ou de fundamentos. Menciona então o "homem racional", o pesquisador (termos não genealogicamente configurados) que ergue duas construções contíguas: sua moradia não passa de uma cabana frágil, signo de penúria e abnegação, apoiada à firme torre da ciência, construção sólida, ascendente, erigida pouco a pouco, com auxílio de homens de ciência, equiparados a um enxame de abelhas laboriosas. O pesquisador constrói sua choupana junto à torre da ciência tanto para colaborar em sua edificação quanto para encontrar proteção e escorar-se em suas muralhas.

O mundo rígido e regular erguido pela razão tecnocientífica aparece então como uma fortaleza construída pela indigência, pela debilidade que necessita do anteparo de obras monumentais progressivamente erigidas, capazes de durar quando o pesquisador e sua cabana já tiverem deixado de existir. Para outro tipo de vivente, que Nietzsche chama então (e ainda não genealogicamente) de "homem intuitivo", e que reconhece nos gregos antigos, a monstruosa armação de conceitos, com suas tábuas de salvação a que se agarra o necessitado ao longo de toda a vida, transforma-se em andaime e em brinquedo. Como andaime, a obra surge agora duplamente afastada, em sua leveza, das construções rígidas que se pretendem perenizar. Por um lado, ela é provisória, simples ponto de apoio para a invenção de novas construções. Nem se quer definitiva nem se arma como um fim em si mesma. Monta-se para ser em seguida desmontada ou deslocada, tão logo perca sua função transitória. Por outro, é um artifício que, se afirmando como tal, não se detém ante o já construído, nem se confunde narcisicamente com a obra, concedendo-lhe estatuto definitivo. Nas mãos do "homem intuitivo", movido pela pulsão de jogar e de brincar (Spieltrieb), as duras armações dos conceitos voltam a se tornar tábuas utilizadas em favor de novas criações. Obras que não pretendem se eternizar como monumentos.

Se, portanto, construir é preciso, há que se avaliarem as construções. Investigar em que medida elas são tributárias do medo e de sua espiral alucinante. Também teoricamente, cabe estimar a que servem nossas construções, sobretudo em um campo ainda tão jovem quanto o dos estudos em Comunicação e Cultura, por vezes por demais cioso em construir firmes edificações identitárias, em vez de nutrir-se de seu inacabamento produtivo, ao modo dos andaimes. Esperemos então que aqui também se exprima uma construção teórica que não se pretenda uma torre científica, um rígido edifício conceitual, sepulcro do gesto inventivo, mas um andaime. Ou, como queria igualmente Nietzsche e parafraseando o final do Elogio de Helena, atribuído ao antigo sofista grego Górgias, que sirva como brinquedo, não movido pelo medo, por um desejo de garantias e seguranças sem risco, mas arriscando-se na pulsão de brincar e de inventar construções provisórias. Ativando a alegria implicada no viver, tais obras talvez funcionem como arma eficaz contra as prisões e armadilhas do medo. Desse modo, o gesto teórico pode, ele mesmo, 
tanto analisar as construções que se tornam reféns do medo quanto valer, em si mesmo, como um desmonte salutar dos labirintos ardilosos de afetos que aqui nomeamos como "medo".

Maria Cristina Franco Ferraz é professora Titular de Teoria da Comunicação da UFRJ, doutora em Filosofia pela Sorbonne, pesquisadora do CNPq e autora de Ruminações: cultura letrada e dispersão hiperconectada (Rio, 2015), L'homme effaçable - mémoire et oubli du XIXe siècle à nos jours (Paris, 2015), Homo deletabilis - corpo, percepção, esquecimento: do século XIX ao XXI (Rio, 2010), Platão: as artimanhas do fingimento (Lisboa, 2010/Rio, 1999), Nove variações sobre temas nietzschianos (Rio, 2002), Nietzsche, le bouffon des dieux/Nietzsche, o bufão dos deuses (Paris, 1998/Rio, 1994).

mcfferraz@hotmail.com

\section{Referências}

AGAMBEN, G. O poder soberano e a vida nua - Homo Sacer. Lisboa: Editorial Presença, 1998.

BADIOU, A. Éloge de L'amour. Paris, Seuil, 2010.

BARTHES, R. Fragmentos de um discurso amoroso. São Paulo: Martins, 2003.

BECK, U. Sociedade de risco: rumo a uma outra modernidade. São Paulo: Editora 34, 2011.

BERGSON, H. Matière et mémoire. Paris: PUF, 2001.

CASTRO, E. V. “O medo dos outros". São Paulo: Revista de Antropologia da USP, volume 54, n², 2011.

CRARY, J. 24/7: late capitalism and the ends of sleep. Londres/Nova York: Verso, 2013.

DELEUZE, G. L'Abécédaire de Gilles Deleuze. DVD com Claire Parnet, produzido por Pierre-André Boutang. Paris: Montparnasse, 2004.

Conversações. Rio de Janeiro: Editora 34, 1992.

Kafka: Pour une littérature mineure. Paris: Minuit, 1975.

Qu'est-ce que la philosophie? Paris: Minuit, 1991.

FERRAZ, M. C. F. Homo deletabilis. Rio de Janeiro: Garamond/FAPERJ, 2010.

FOUCAULT, M. História da sexualidade I. Rio de Janeiro: Graal, 2009.

GÓRGIAS. "Elogio de Helena". In: Cadernos de tradução, número 4. São Paulo: Departamento de Filosofia da USP, 1999.

KAFKA, F. "A construção". In: Um artista da fome / A construção. Tradução de Modesto Carone. São Paulo: Brasiliense, 1984. 
Das erzählerische Werk vol. I. Berlim: Rütten \& Loening, 1988.

NIETZSCHE, F. Além do bem e do mal. São Paulo: Companhia das Letras, 1992.

. Das Philosophenbuch/Le livre du philosophe. Paris: Aubier-Flammarion, 1969.

Genealogia da moral. São Paulo: Companhia das Letras, 1998.

Sämtliche Werke (KSA, 15 vol.). Berlim/Nova York: DTV/de Gruyter, 1988.

RIBEIRO, R. J. Ao leitor sem medo: Hobbes escrevendo contra o seu tempo. Belo Horizonte: Ed. UFMG (Coleção Humanitas), 1999.

ROSA, J. G. Primeiras estórias. Rio de Janeiro: José Olympio, 1969.

TUCHERMAN, I. "Nem toda forma de amor vale a pena ou Paixão é cocaína, amor é Rivotril". Brasília: XXIV Encontro da Compós, 2015.

VAZ, P.; CARDOSO, J. "A epidemia da dengue como questão política: risco e sofrimento no Jornal Nacional em 2008". Porto Alegre: XX Encontro da Compós, 2011.

ŽIŽEK, S. Bem-vindo ao deserto do real!: cinco ensaios sobre o 11 de setembro e datas relacionadas. São Paulo: Boitempo, 2003. 